\title{
BLOCKADE OF LONG-TERM POTENTIATION IN RAT HIPPOCAMPAL CA1 REGION BY INHIBITORS OF PROTEIN SYNTHESIS ${ }^{1}$
}

\author{
P. K. STANTON AND J. M. SARVEY ${ }^{2}$ \\ Department of Pharmacology, Uniformed Services University of the Health Sciences, Bethesda, Maryland 20814
}

Received March 5, 1984; Revised May 24, 1984; Accepted June 15, 1984

\begin{abstract}
Long-term potentiation (LTP) in the hippocampus has attracted attention as a model of neuronal plasticity in the central nervous system. Although accumulating evidence associates protein synthesis with LTP, there is no direct proof that protein synthesis is actually required for the production of LTP. Therefore, we have examined the ability of some inhibitors of protein synthesis to modify LTP in the CA1 region of the rat hippocampal slice.

Incubation for $30 \mathrm{~min}$ in the presence of emetine, cycloheximide, or puromycin decreased the frequency of occurrence of LTP in field CA1 elicited by repetitive stimulation of the Schaffer collaterals. This blockade was dose dependent and correlated with the ability of individual inhibitors to inhibit incorporation of $\left[{ }^{3} \mathrm{H}\right]$ valine into proteins. LTP blockade was irreversible for the irreversible inhibitor emetine and was reversible for the reversible inhibitor cycloheximide. Blockade of LTP required a substantial preincubation period to be effective. Even at the highest concentration of emetine used to block LTP, no effect on any intracellularly recorded membrane properties was observed. In contrast, the protein synthesis inhibitor anisomycin was unable to block LTP. Puromycin aminonucleoside, a structural analogue of puromycin which is inactive in inhibiting protein synthesis, was ineffective in blocking LTP.

These experiments demonstrate that a variety of protein synthesis inhibitors are able to block the production of LTP in field CA1, suggesting the necessity for a set of newly synthesized or rapidly turned over proteins for hippocampal LTP.
\end{abstract}

In the hippocampus, brief, high frequency stimulation of afferents gives rise to a long-lasting increase in the amplitude of the evoked population action potential (population spike). This phenomenon has been called long-term potentiation (LTP) and has been described for a number of neuronal inputs to the hippocampus (Bliss and Lømo, 1973; Schwartzkroin and Wester, 1975; Alger and Teyler, 1976). The amplitude of the postsynaptic population spike is up to 10 times greater than the response prior to repetitive stimulation (Schwartzkroin and Wester, 1975). LTP can last for weeks in the intact animal (Bliss and Garnder-Medwin, 1973; Douglas and Goddard, 1975), and for the life of the hippocampal slice (up to $10 \mathrm{hr}$ or longer) (Alger and Teyler, 1976; Andersen et al., 1977). The extremely long duration of hippocampal LTP, and the possible involvement of the hippocampus in memory processes (Milner,

\footnotetext{
${ }^{1}$ This work was supported by Uniformed Services University of the Health Sciences Grant CO7514. We thank Dr. Jeffrey M. Harmon for his invaluable advice and assistance with the $\left[{ }^{3} \mathrm{H}\right]$ valine incorporation methodology, his advice in experimental design, and for many valuable discussions and suggestions for improving the manuscript. Also, we thank Dr. Terry C. Pellmar, Dr. Andrew M. Williamson, and Helen Scharfman for their advice with earlier manuscript versions. Special thanks go to Dr. Sol D. Erulkar for insightful comments on the manuscript. The expert technical assistance of Ms. Georgette Yakalis and Ms. Kelley Baione is most gratefully acknowledged.

${ }^{2}$ To whom correspondence should be addressed.
}

1972), has led to speculation that LTP may provide a model for learning and memory.

Repetitive high frequency stimulation of the hippocampus produces numerous biochemical effects, including changes in protein phosphorylation patterns (Bär et al., 1982), increases in specific protein fractions (Browning et al., 1979), and increased secretion of newly synthesized proteins (Duffy et al., 1981). However, it is not known whether synthesis of proteins is required for, or merely a by-product of, LTP.

Therefore, we investigated the ability of a variety of inhibitors of protein synthesis to block LTP in field CA1 of the hippocampal slice. In addition, we measured the inhibition of $\left[{ }^{3} \mathrm{H}\right]$ valine incorporation into proteins in slices by the various protein synthesis inhibitors. We report here that the protein synthesis inhibitors emetine, cycloheximide, and puromycin are all effective in blocking LTP in field CA1 of the hippocampus. Concentrations effective in blocking LTP correlated well with concentrations needed to inhibit $\left[{ }^{3} \mathrm{H}\right]$ valine incorporation into proteins. In contrast, the protein synthesis inhibitor anisomycin was unable to block LTP at concentrations that were effective in inhibiting incorporation of $\left[{ }^{3} \mathrm{H}\right]$ valine. A preliminary version of this work has been reported previously (Stanton and Sarvey, 1983).

\section{Materials and Methods}

Animals. Male Sprague-Dawley rats (200 to $350 \mathrm{gm}$ ) were obtained from Hilltop Lab Animals, Inc. (Scottsdale, PA).

Materials. Emetine, cycloheximide, puromycin, anisomycin and $\alpha$ methyl-p-tyrosine were obtained from Sigma Chemical Co. (St. Louis, 
MO). L $\left[3,4(n)-{ }^{3} \mathrm{H}\right]$ Valine $(36 \mathrm{Ci} / \mathrm{mmol})$ in $2 \%$ EtOH was obtained from Amersham Corp. (Arlington Heights, IL). Puromycin aminonucleoside was obtained from ICN Pharmaceuticals Division (Cleveland, $\mathrm{OH}$.

Electrophysiology. Transverse hippocampal slices (375 $\mu \mathrm{m}$ thick) were prepared with a McIlwain tissue chopper (Brinkmann Instruments, Inc., Westbury, NY). Slices were placed on a nylon net at the interface between buffer and a humidified atmosphere of $95 \% \mathrm{O}_{2} / 5 \%$ $\mathrm{CO}_{2}$ and were continuously perfused at $35^{\circ} \mathrm{C}$ and $\mathrm{pH} 7.2$. The modified Krebs-Ringer buffer had the following ionic composition (in millimolar concentration): $\mathrm{NaCl}, 124 ; \mathrm{KCl}, 5 ; \mathrm{MgSO}_{4}, 1.3 ; \mathrm{KH}_{2} \mathrm{PO}_{4}, 1.25 ; \mathrm{NaHCO}_{3}$, 26; glucose, $10 ; \mathrm{CaC}_{2}$ was titrated to give a free $\left[\mathrm{Ca}^{2+}\right]$ of $2.2 \mathrm{mM}$, as measured by a $\mathrm{Ca}^{2+}$-sensitive electrode.

Slices were capable of producing stable orthodromic responses for at least $8 \mathrm{hr}$. Stimuli were delivered with bipolar electrodes placed on the Schaffer collateral axon fibers in stratum radiatum, and orthodromic field potentials were recorded with glass microelectrodes $(2 \mathrm{M} \mathrm{NaCl}, 2$ to 5 megohms) placed in the CAI cell body layer.

Drugs were applied extracellularly at known concentrations by switching perfusion reservoirs. All drugs were directly soluble in physiologic buffer at all concentrations employed. The perfusion flow rate was maintained at $3 \mathrm{ml} / \mathrm{min}$ with a peristaltic pump. All drug application times were corrected for transit time from the reservoirs to the slice $(5 \mathrm{~min})$.

Prior to repetitive stimulation, slices were incubated for $60 \mathrm{~min}$, and a base line input-output $(\mathrm{I} / \mathrm{O})$ relation between stimulus intensity and population spike amplitude was determined. Then, one of the protein synthesis inhibitors was added to the perfusate and slices were incubated in the presence of that inhibitor for an additional $30 \mathrm{~min}$. During this time, the $\mathrm{I} / \mathrm{O}$ remained stable. Slices were stimulated repetitively at a frequency of $20 \mathrm{~Hz}$ for $10 \mathrm{sec}$ with an intensity that had evoked a population spike of approximately $20 \%$ of the maximal base line response. $\mathrm{I} / \mathrm{O}$ curves were determined at 2,15 , and $30 \mathrm{~min}$ after repetitive stimulation.

Measurement of $\left[{ }^{3} \mathrm{H}\right]$ valine incorporation into proteins in slices. The level of inhibition of protein synthesis in slices was measured by incorporation of $\left[{ }^{3} \mathrm{H}\right]$ valine into trichloroacetic acid (TCA) -precipitable macromolecules (Lipton and Heimbach, 1977). Slices were prepared identically to those used for electrophysiology and then placed in $1 \mathrm{ml}$ of buffer ( $\mathrm{pH} 7.2$ to 7.4 ) in 24 well tissue culture dishes (Costar). Slices were preincubated for $60 \mathrm{~min}$ at $37^{\circ} \mathrm{C}$ in a humidified atmosphere of $95 \%$ air $/ 5 \% \mathrm{CO}_{2}$. Inhibitors were then added to the wells for a $30-\mathrm{min}$ incubation, after which $\left[{ }^{3} \mathrm{H}\right]$ valine (final concentration, $1 \mu \mathrm{Ci} / \mathrm{ml}$ ) was added. After an additional $60 \mathrm{~min}$, incorporation was terminated by dilution of the isotope in unlabeled valine (final concentration $0.1 \mathrm{mg} /$ $\mathrm{ml}$ ) and homogenization in $10 \% \mathrm{TCA}$ at $4{ }^{\circ} \mathrm{C}$, followed by centrifugation at $12,000 \times g$. Pellets were washed twice in $5 \%$ TCA, centrifuged at $12,000 \times \mathrm{g}$, and resuspended in $5 \%$ TCA, and all supernatants were discarded. The pellets were resolubilized in $1 \mathrm{~N} \mathrm{NaOH}$ overnight at $37^{\circ} \mathrm{C}$ and neutralized in $1 \mathrm{~N} \mathrm{HCl}$, and aliquots were taken for determination of radioactivity by liquid scintillation methods using a Beckman LS 7800 scintillation counter. Protein was determined by the method of Lowry et al. (1951), and results were expressed as disintegrations per minute per milligram of protein. Percentage inhibition of $\left[{ }^{3} \mathrm{II}\right]$ valine incorporation produced by drug treatments was calculated by comparing incorporation in treated slices with incorporation in control slices in the same tissue culture plates. It has been shown previously that incorporation of $\left[{ }^{3} \mathrm{H}\right]$ valine into proteins with this methodology is linear for at least $60 \mathrm{~min}$ (Lipton and Heimbach, 1977), and we have verified this in our assay system.

Data analysis methods. Spike amplitude was defined as the average of the amplitude from the peak early positivity to the peak negativity, and the amplitude from the peak negativity to the peak late positivity (Alger and Teyler, 1976). Population spike amplitude has been shown to reflect the number and synchrony of neurons firing in the vicinity of the recording electrode (Andersen et al., 1971), and to correlate with the slope of the excitatory postsynaptic potential as well as with spike latency (Bliss and Gardner-Medwin, 1973). LTP was defined as a spike amplitude increase of greater than $2 \mathrm{SD}$ from the mean of three control base lines ( $>35 \%$ increase) $30 \mathrm{~min}$ after repetitive stimulation, since in slices which showed potentiation at this time, potentiation lasted for hours (Fig. 1C). An earlier time was not chosen because large spike amplitude increases often occur immediately after repetitive stimulation and last up to $15 \mathrm{~min}$ in the absence of LTP. Therefore, we defined a spike amplitude increase of $2 \mathrm{SD}$ ( $>35 \%$ increase) observed $2 \mathrm{~min}$ after repetitive stimulation as short-term potentiation (STP). Extracellular responses were sampled on line by a digitizing oscilloscope (Tektronix 7D20), transferred to a MINC 11/23 computer (Digital Equipment Corp., Marlboro, MA), and stored as the average of eight responses.

All values in the text are expressed as mean \pm SEM. Comparison of the frequency of occurrence of LTP was evaluated by $\chi^{2}$ test, comparing all groups to the control frequency of occurrence of LTP in this study $(57 \%)$. Comparison of pre- and post-stimulation responses in the same slices, and of the effects of emetine on intracellular parameters, was evaluated by $t$ test for paired observations. The level of significance for all statistical tests was preselected to be $p<0.05$. Linear regression was performed by Newton's method of least squares linear analysis (Goldstein, 1964).

\section{Results}

Blockade of LTP in hippocampal slices by protein synthesis inhibitors. Figure 1 illustrates the population spike in field CA1 before and $30 \mathrm{~min}$ after a single train of repetitive stimuli to the Schaffer collaterals. An example of control LTP of approximately $200 \%$ increase in amplitude is shown in Figure $1 A$. In Figure $1 B$, emetine $(1.5 \mu \mathrm{M})$ was added to another slice $30 \mathrm{~min}$ prior to repetitive stimulation and was present continuously until measurement of LTP $30 \mathrm{~min}$ after repetitive stimulation. During this time, the base line response remained stable. LTP was completely blocked, and the population spike was unaltered. Figure $1 C$ illustrates the time course of typical changes in population spike amplitude after repetitive stimulation for a control potentiated slice and for a slice treated with emetime $(1.5 \mu \mathrm{M})$. Although LTP was routinely assessed $30 \mathrm{~min}$ after repetitive stimulation, this time course demonstrates that the response can remain potentiated for at least $5 \mathrm{hr}$. Furthermore, emetine had no effect on the population spike over the 5 -hr period.

Three protein synthesis inhibitors were effective in blocking production of LTP in CA1 in a dose-dependent manner. Slices were preincubated for $30 \mathrm{~min}$ with one of the protein synthesis inhibitors, emetine, cycloheximide, or puromycin. The Schaffer collaterals were then repetitively stimulated, and the slices were maintained in the drug solution for an additional $30 \mathrm{~min}$; after this time, population spike amplitude was measured. The percentage of slices exhibiting ITP in control versus drug conditions is shown in Figure $2 A$. Note that, in control conditions, $57 \%$ of the slices exhibited LTP.

The intermediate and high concentrations of emetine and cycloheximide, and the high concentration of puromycin, were all able to significantly decrease the frequency of LTP observed in CA1 $\left(\chi^{2}, p<0.05\right)$. In contrast, the low concentrations of all three inhibitors did not significantly decrease the frequency of LTP. There were no alterations in population spike waveform or amplitude produced by any of the three inhibitors over the course of the experiments, with the exception of the highest concentration of cycloheximide $(35 \mu \mathrm{M})$, which occasionally produced a transient increase in spike amplitude, followed by at most a $20 \%$ depression. The effect of puromycin $(100 \mu \mathrm{M})$ on the population spike was followed for longer time periods. Puromycin had no effect on population spike waveform or amplitude for periods up to $3 \mathrm{hr}(N=4)$, but multiple population spikes were occasionally observed after this time.

The blockade of LTP by these inhibitors is specific to the long-lasting enhancement of synaptic efficacy in LTP. STP, often observed immediately after repetitive stimulation, was not affected by inhibition of protein synthesis. STP seen $2 \mathrm{~min}$ after repetitive stimulation (in 8 of 28 slices, 29\%) was not altered by the highest concentration of any of the three synthesis inhibitors (14 of 26 slices, $54 \%$ ), even though LTP did not occur.

Measurement of protein synthesis in slices by $\left[{ }^{3} H\right]$ valine incorporation into TCA-precipitable macromolecules. Measure- 

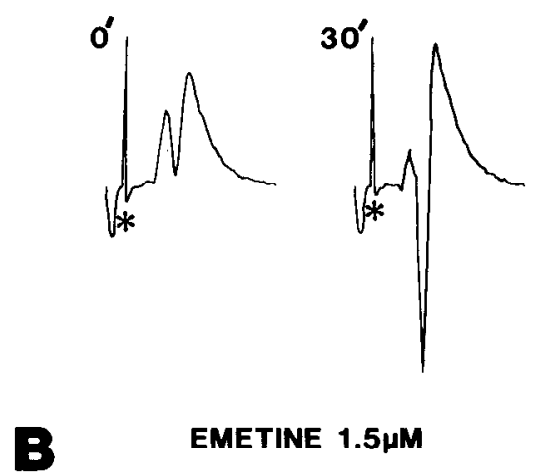

\section{EMETINE $1.5 \mu \mathrm{M}$}
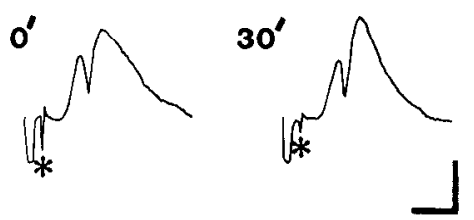

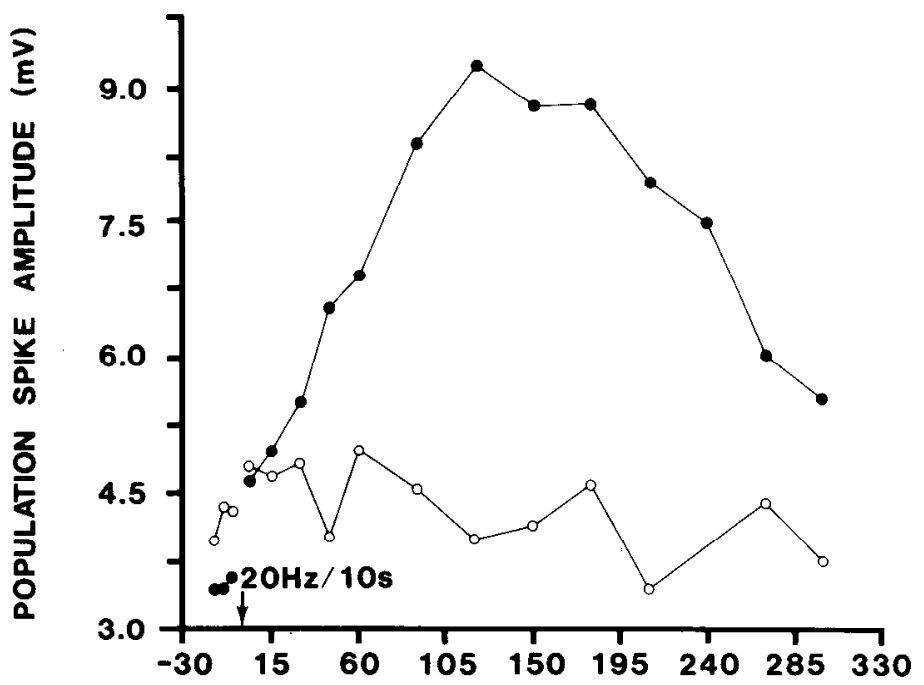

TIME (min)

Figure 1. A, Control LTP in field CA1. The population spike was recorded in CA1 just before $\left(\sigma^{\prime}\right)$ and 30 min after $\left(30^{\prime}\right)$ repetitive stimulation of the Schaffer collaterals ( $20 \mathrm{~Hz} / 10$ sec; arrow in $C$ ). Asterisks denote stimulus artifact. $B$, Blockade of LTP in field CA1 by emetine. The slice was pretreated with the protein synthesis inhibitor emetine $(1.5 \mu \mathrm{M})$ for $30 \mathrm{~min}$ before repetitive stimulation $(20 \mathrm{~Hz} / 10 \mathrm{sec})$, and the inhibitor remained in the medium until measurement of LTP 30 min after repetitive stimulation. LTP was completely blocked, and the population spike amplitude was unchanged $30 \mathrm{~min}$ after repetitive stimulation. Calibration for $A$ and $B, 1 \mathrm{mV}, 5 \mathrm{msec} . C$, The time course of the increase in population spike amplitude in control LTP is compared to the time course of blockade of LTP with emetine (15 $\mu \mathrm{M})$. These are different slices from $A$ and $B$. The control slice $(\odot)$ saw no inhibitor and was repetitively stimulated at time zero $\left(0^{\prime}, 20 \mathrm{~Hz} / 10 \mathrm{sec} ;\right.$ arrow). The treated slice (O) received bath application of emetine $(15 \mu \mathrm{M})$ throughout the experiment and was repetitively stimulated in an identical manner. In the control slice, LTP was clearly established at $30 \mathrm{~min}$, peaked after $2 \mathrm{hr}$, and lasted throughout the 5-hr recording period. In the treated slice, no LTP occurred, and the response was stable throughout the 5-hr recording period.

ment of the level of inhibition of $\left[{ }^{3} \mathrm{H}\right]$ valine incorporation into proteins achieved in slices was performed to determine whether the percentage inhibition correlated with the dose dependence of blockade of LTP (Fig. $2 B$ ). Slices were preincubated for 30 $\mathrm{min}$ with one of the three protein synthesis inhibitors prior to the addition of $\left[{ }^{3} \mathrm{H}\right]$ valine $(1 \mu \mathrm{Ci} / \mathrm{ml})$ to the medium. Uptake and incorporation of $\left[{ }^{3} \mathrm{H}\right]$ valine into proteins was allowed to proceed for an additional $60 \mathrm{~min}$. Incorporation into TCAprecipitable proteins was measured as a percentage of untreated slices.

These inhibitors blocked protein synthesis in a dose-dependent manner. At concentrations which were effective in blocking LTP, the mean percentage inhibition of protein synthesis was $93 \pm 1.2 \%(N=26)$. At the low concentrations, which were ineffective in blocking LTP, the mean percentage inhibition of protein synthesis was only $60 \pm 7.7 \%$. $(N=14)$. The degree of blockade of LTP produced by each of the three inhibitors was found to correlate $(r=-0.843, p<0.05)$ with the attenuation of incorporation of $\left[{ }^{3} \mathrm{H}\right]$ valine into proteins. Regression analysis of the amplitude of the population spike $30 \mathrm{~min}$ after repetitive stimulation as percentage of prestimulation amplitude versus inhibition of incorporation of $\left[{ }^{3} \mathrm{H}\right]$ valine also exhibited a significant correlation $(r=-0.737, p<0.05)$. The mean percentage inhibition of protein synthesis at concentrations that block LTP suggest that almost complete inhibition of protein synthesis is necessary to impair the production of LTP.

Blockade of LTP by emetine requires a preincubation period. In a variety of cellular systems, protein synthesis inhibitors are found to require several minutes to penetrate the cell, bind to ribosomes, and inhibit protein synthesis (Grollman, 1968). If protein synthesis inhibition is the mechanism of LTP blockade, we would expect a preincubation period to be necessary for effective blockade. Conversely, if a faster-acting property of these inhibitors is the mechanism of LTP blockade, we would expect the presence of the inhibitor during and after the repetitive stimulation to be sufficient to block LTP.

As shown in Figure 3, blockade of LTP by emetine did require the 30 -min preincubation period. If repetitive stimulation was delivered as emetine arrived in the bath, LTP was no longer blocked. ( $N=11)$. In contrast, LTP did not occur when emetine was added $30 \mathrm{~min}$ before repetitive stimulation $\left(N=15, \chi^{2}, p\right.$ $<0.05$ ).

These results show that blockade of LTP by emetine is not simply a result of nonspecific membrane effects since, when emetine was present in the bath only from the time of repetitive stimulation, and for 30 min after, LTP was no longer blocked.

Reversibility of protein synthesis inhibition and blockade of $L T P$. To establish further that these inhibitors block LTP by inhibiting protein synthesis, we determined whether differences in the reversibility of their inhibition of protein synthesis were matched by differences in reversibility of their blockade of LTP. Emetine is an irreversible inhibitor of protein synthesis, whereas cycloheximide is a reversible inhibitor of protein synthesis (Grollman, 1968). Measurement of $\left[{ }^{3} \mathrm{H}\right]$ valine incorporation in slices verified this observation. Slices were treated with the same incubation and wash paradigm, shown in Figure $4 A$. Inhibition by emetine of $\left[{ }^{3} \mathrm{H}\right]$ valine incorporation in slices was not reversed by a 2 -hr wash, whereas inhibition by cycloheximide was reversible.

Figure $4 B$ illustrates that the differences in reversibility also apply to the blockade of LTP. As usual, preincubation for 30 min with either emetine $(1.5 \mu \mathrm{M})$ or cycloheximide $(3.5 \mu \mathrm{M})$ blocked the induction of LTP $\left(\chi^{2}, p<0.05\right)$. These same slices were then washed in drug-free buffer for $2 \mathrm{hr}$, after which a second repetitive stimulation was applied. Slices treated with the irreversible protein synthesis inhibitor emetine were still unable to potentiate $\left(N=4, \chi^{2}, p<0.05\right)$. However, slices 


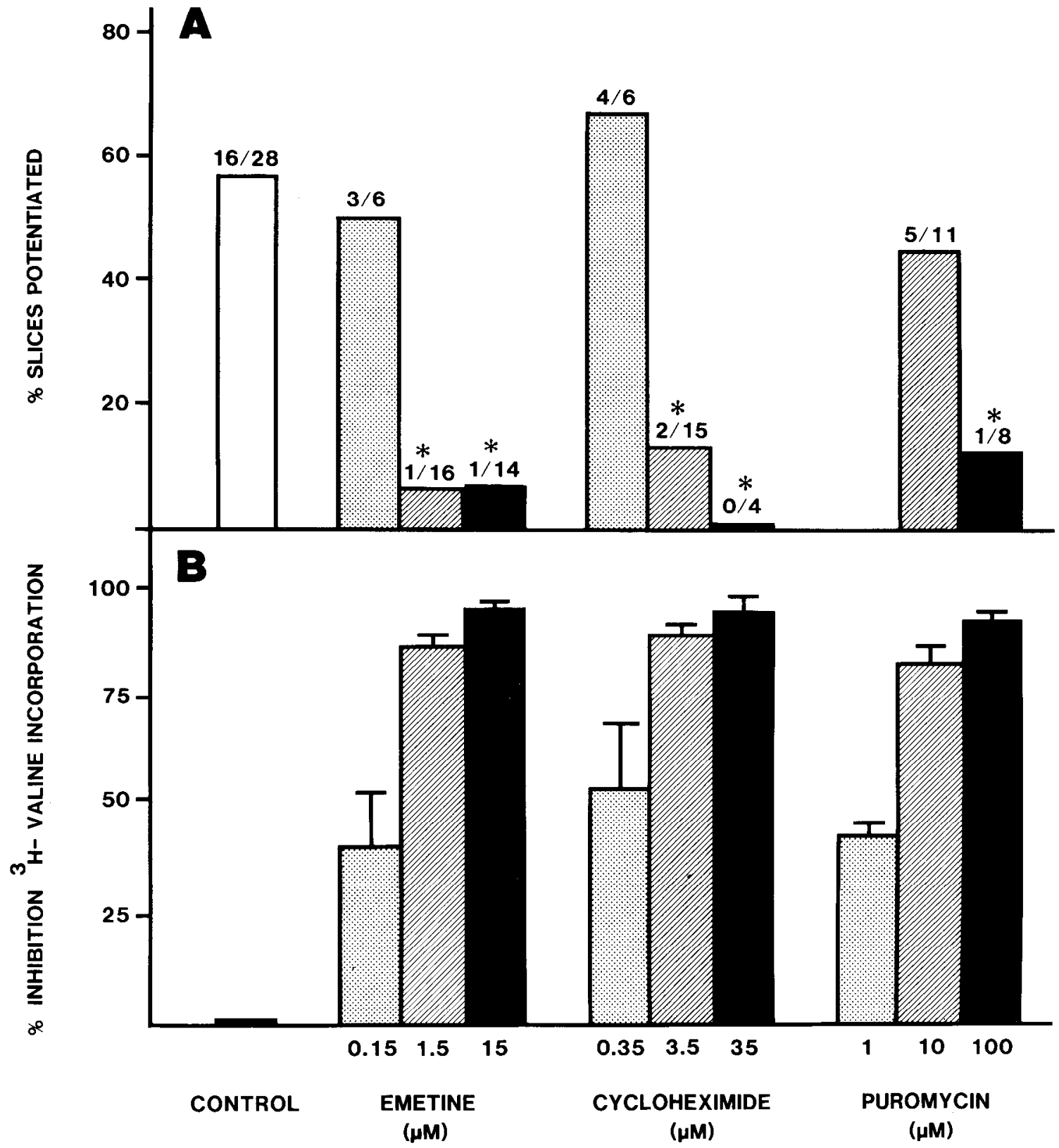

Figure 2. A, Percentage of LTP in the presence of each of three protein synthesis inhibitors in the bath, compared to control incidence of LTP. Above each bar is the number of slices showing LTP per total number of slices tested. LTP was defined as having occurred when an increase in population spike amplitude greater than $2 \mathrm{SD}(>35 \%)$ over mean control base line amplitudes was observed 30 min after repetitive stimulation. Whereas the lowest concentration of each inhibitor was ineffective in blocking LTP, higher concentrations of each inhibitor significantly decreased the frequency of occurrence of LTP $\left(* ; x^{2}, p<0.05\right)$. B. Percentage inhibition of $\left[{ }^{3} \mathrm{H}\right]$ valine incorporation into TCAprecipitable macromolecules by each protein synthesis inhibitor. Slices were incubated in tissue culture wells for 30 min in one of the protein synthesis inhibitors, and then $\left[{ }^{3} \mathrm{H}\right]$ valine $(1 \mu \mathrm{Ci} / \mathrm{ml})$ was added and the slices were incubated for an additional 60 min. Incorporation into proteins was halted by homogenization in excess unlabeled valine $(0.1 \mathrm{mg} / \mathrm{ml})$ at $4^{\circ} \mathrm{C}$, and TCA-precipitable macromolecules were separated and counted. Incorporation was expressed as disintegrations per minute per milligram of protein, and percentage inhibition was calculated compared to internal standard slices that receive no inhibitor in the same plate.

treated with the reversible inhibitor cycloheximide were capable of exhibiting LTP after the wash $(N=3)$. These results further support a link between LTP blockade and inhibition of protein synthesis. In addition, the ability of these slices to support LTP after cycloheximide treatment and wash convincingly demonstrates the viability of these slices, in spite of prolonged inhibition of protein synthesis.

Puromycin aminonucleoside does not block LTP or inhibit protein synthesis in slices. If inhibition of protein synthesis is essential for blockade of LTP, congeners of these compounds which are inactive in inhibiting protein synthesis should not be able to block LTP. Puromycin aminonucleoside (PA) is such a structural analogue of puromycin that is relatively ineffective in inhibiting protein synthesis (Agranoff et al., 1966). Experiments with PA are summarized in Figure 5. Measurement of $\left[{ }^{3} \mathrm{H}\right]$ valine incorporation in slices treated with PA $(100 \mu \mathrm{M})$ verified that it has very limited potency in inhibiting protein synthesis $(17.3 \pm 10.2 \%, N=2)$. When added to slices for 30 min before repetitive stimulation, PA $(100 \mu \mathrm{M})$ was unable to prevent the induction of LTP $(N=8)$. In contrast, the same concentration of puromycin was effective in blocking LTP $(N$ $\left.=8, \chi^{2}, p<0.05\right)$. These results support the conclusion that puromycin blocks LTP by inhibiting protein synthesis.

Tyrosine hydroxylase inhibition is not responsible for blockade 


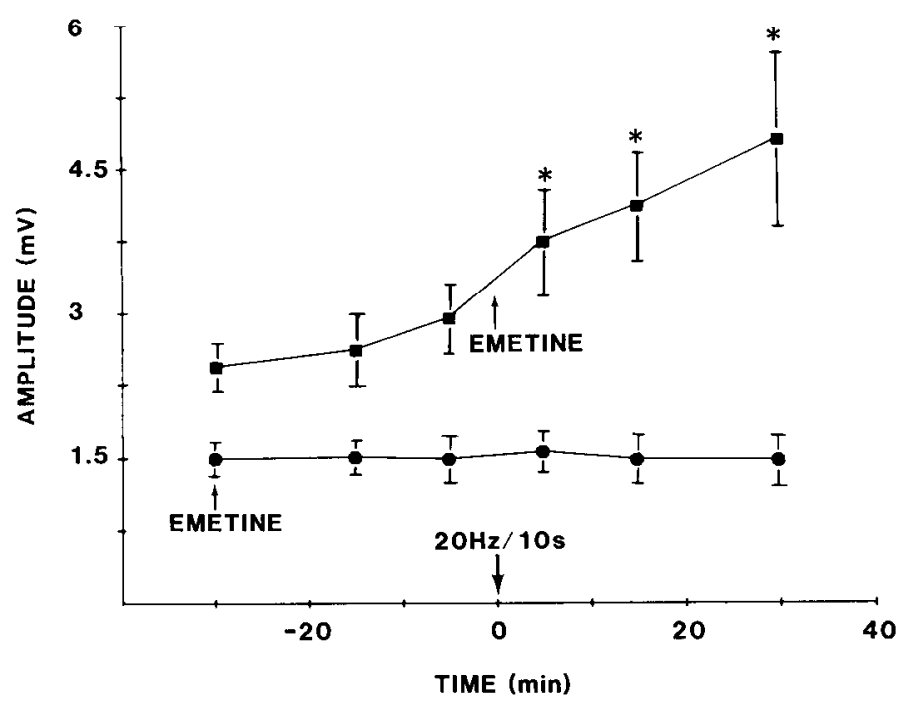

Figure 3. Time lag in LTP blockade by emetine. Population spike amplitudes of responses recorded in CA1 before, and 2, 15, and $30 \mathrm{~min}$ after repetitive stimulation of the Schaffer collaterals $(20 \mathrm{~Hz} / 10 \mathrm{sec}$; large arrow). Emetine $(1.5 \mu \mathrm{M} ;$ small arrow $)$ was added to the bath 30 min before $(0)(N=15)$ or simultaneous with $(\mathbb{G})(N=11)$ the repetitive stimulation, and was present the entire time thereafter. Blockade of LTP by emetine did require the preincubation period, since simultaneous addition failed to block LTP ( $*$; paired $t$ test, $p<0.05$ ).

of LTP by protein synthesis inhibitors. Inhibition of catecholamine synthesis is a side effect of cycloheximide, puromycin, and anisomycin, which has heen suggested as a possible mechanism of their behavioral effects (Flexner and Goodman, 1975). Other studies have indicated that inhibition of tyrosine hydroxylase, the rate-limiting enzyme in catecholamine synthesis, is not responsible for the behavioral effects of protein synthesis inhibitors (Squire et al., 1974). The possibility that inhibition of catecholamine synthesis by protein synthesis inhibitors might be responsible for blockade of LTP was evaluated by bath applying $\alpha$-methyl-p-tyrosine (AMPT; $100 \mu \mathrm{M}$ ), an irreversible inhibitor of tyrosine hydroxylase. A 30-min preincubation with AMPT was unable to block LTP in CA1 $(N=8)$. Therefore, inhibition of catecholamine synthesis cannot be responsible for blockade of LTP in field CA1.

Intracellularly recorded membrane parameters are not affected by emetine. There have been suggestions that some protein synthesis inhibitors may exhibit nonspecific neuronal membrane depressant effects. Of the inhibitors we employed to block LTP, emetine seems to be lacking in such nonspecific membrane effects. As can be seen in Figure $1 B$, emetine (1.5 $\mu \mathrm{M})$ produced no effect on the shape or amplitude of the extracellular response. This would suggest that the only effect of emetine is blockade of LTP. To further ensure that the blockade of LTP was not due to a nonspecific effect on the neuronal membrane too subtle to be seen in the population spike, we recorded intracellularly in the presence of emetine (Table I). We found that even the highest concentration of emetine $(15 \mu \mathrm{M})$ applied for $1 \mathrm{hr}$ produced no changes in resting membrane potential, input resistance, action potential amplitude or duration, EPSP amplitude, IPSP amplitude, threshold for either a synaptically or directly evoked action potential, accommodation to a depolarizing current step, or the $\mathrm{CA}^{21}$ dependent $\mathrm{K}^{+}$afterhyperpolarization $(N=5$, paired $t$ test). Figure 6 shows the extracellular population spike (Fig. 6A), intracellular action potential (Fig. 6B), and response to a depolarizing current step (Fig. $6 \mathrm{C}$ ) in a typical cell before, and $30 \mathrm{~min}$ after, emetine was added. These data make it very unlikely that some generalized alteration of membrane or chan- nel properties leading to altered neuronal excitability is responsible for emetine's blockade of LTP.

Anisomycin is a protein synthesis inhibitor unable to block $L T P$. Reports in the literature have suggested that the pyrrolidine protein synthesis inhibitor anisomycin was unable to block LTP (Swanson et al., 1982). Therefore, we evaluated the ability of anisomycin to modify LTP in field CA1. Anisomycin was added to the bath $30 \mathrm{~min}$ before repetitive stimulation and was present continuously until assessment of LTP 30 min after repetitive stimulation. None of the concentrations employed (3.8 to $190 \mu \mathrm{M}$ ) was able to alter the frequency of occurrence of LTP in field CA1 as tested by $\chi^{2}$ analysis. However, when the population spike amplitude $30 \mathrm{~min}$ after repetitive stimulation was compared by a paired $t$ test with prestimulation amplitude in all slices, including those that failed to meet the criterion for LTP, an average increase in spike amplitude was not seen at any concentration of anisomycin tested. By this criterion, anisomycin blocked LTP. On those occasions when LTP did occur, the average amplitude of LTP in untreated slices was $311 \pm 89.1 \%(N=16$, percentage of prestimulated base line responses), while the amplitude of $\mathrm{I}$. TP in anisomycin-treated slices was $199 \pm 31.2 \%(N=9)$, and the LTP amplitude in those treated with the other inhibitors was $196 \pm 24.1 \%(N=$ 6). Therefore, we conclude that emetine, cycloheximide, and puromycin may be able to decrease both occurrence and amplitude of LTP, whereas anisomycin appears only to decrease LTP amplitude and not prevent its occurrence. 'This suggests a qualitative difference between anisomycin's actions and those of the other protein synthesis inhibitors.

Measurement of anisomycin's inhibition of $\left[{ }^{3} \mathrm{H}\right]$ valine incorporation into TCA-precipitable proteins indicated that all concentrations of anisomycin employed inhibited more than $90 \%$ $(N=6)$.

Further experiments were performed to determine whether a greater time lag in the drug's effectiveness might be responsible for its failure to block LTP. Preincubation in anisomycin for up to $2 \mathrm{hr}$ did not block LTP $(N=4)$. Measurement of anisomycin's ability to inhibit $\left[{ }^{3} \mathrm{H}\right]$ valine incorporation after 2 $\mathrm{hr}$ in oxygenated buffer indicated that there was no significant loss of overall ability to inhibit $\left[{ }^{3} \mathrm{H}\right]$ valine incorporation over time. Finally, we considered the hypothesis that anisomycin might be inhibiting $\left[{ }^{3} \mathrm{H}\right]$ valine incorporation in our assay system by inhibiting cellular uptake of $\left[{ }^{3} \mathrm{H}\right]$ valine, rather than by inhibiting protein synthesis. Therefore, we scparated the intracellular and extracellular $\left[{ }^{3} \mathrm{H}\right]$ valine from that incorporated irto TCA-precipitable proteins and found that cellular uptake of $\left[{ }^{3} \mathrm{H}\right]$ valine was not inhibited by anisomycin.

\section{Discussion}

Several conclusions can be drawn from these studies. (1) Emetine, cycloheximide, and puromycin, protein synthesis inhibitors with dissimilar chemical structures and sites of action, are all effective in preventing the production of LTP in CA1. (2) The dose-response relation for blockade of LTP parallels that for inhibition of incorporation of $\left[{ }^{3} \mathrm{H}\right]$ valine into TCAprecipitable proteins by these compounds. (3) There is a time lag for blockade of LTP which is similar to that necessary for inhibition of protein synthesis. (4) Blockade of LTP and inhibition of protein synthesis are either both essentially irreversible, as with emetine, or both reversible, as with cycloheximide. (5) PA, an inactive analogue of puromycin, is ineffective in blocking LTP. (6) Inhibition of catecholamine synthesis is nut responsible for blockade of LTP in CA1. (7) Intracellular recordings reveal no nonspecific membrane effects of emetine even at the highest concentrations used to block LTP. (8) Anisomycin is a protein synthesis inhibitor which is ineffective in blocking the production of LTP. 


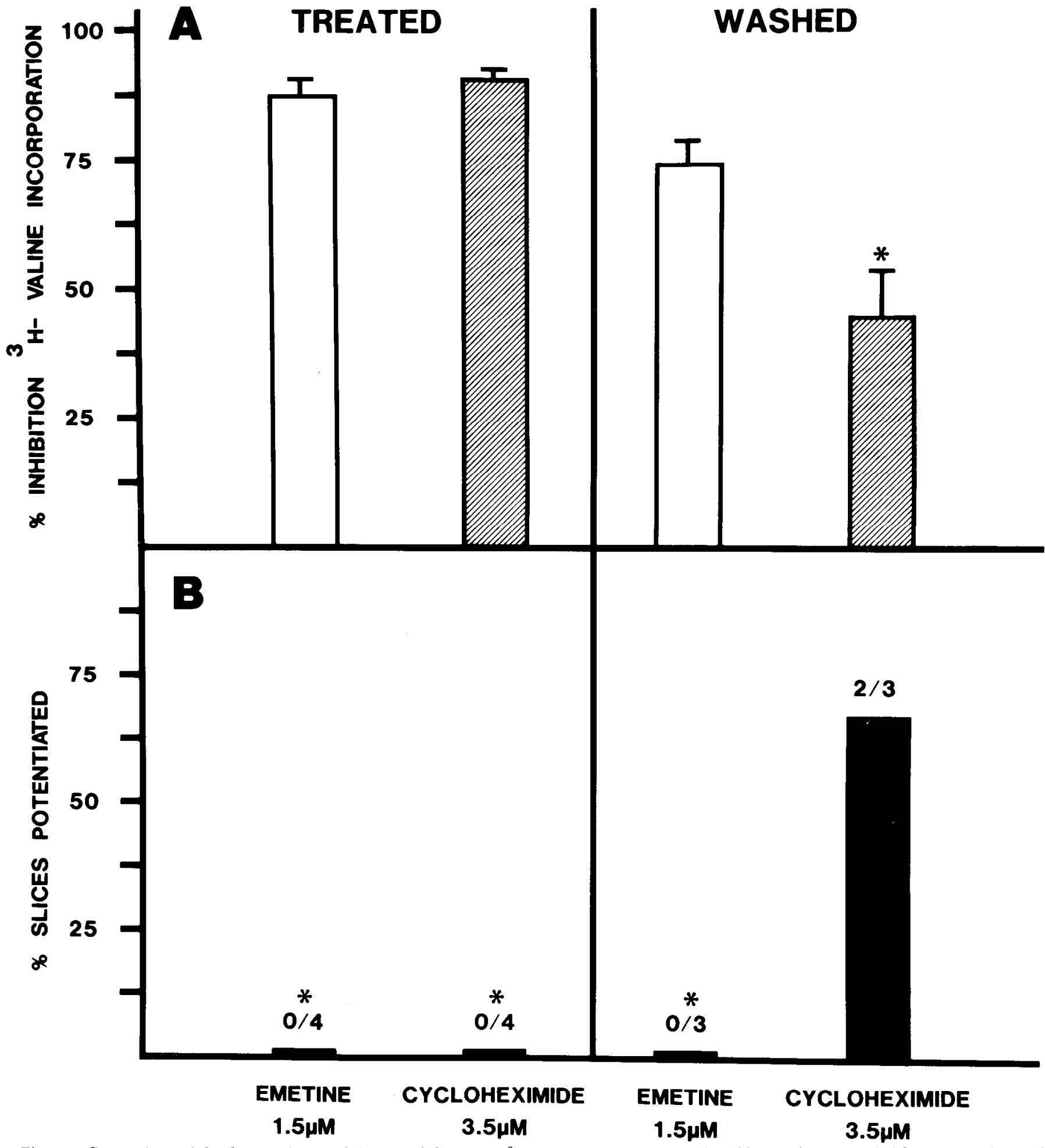

Figure 4. Comparison of the degree of reversibility of inhibition of $\left[{ }^{3} \mathrm{H}\right]$ valine incorporation $(A)$ and blockade of LTP $(B)$ by emetine $(1.5 \mu \mathrm{M})$ and cycloheximide $(3.5 \mu \mathrm{M})$. A, TREATED: Slices incubated $30 \mathrm{~min}$ in emetine or cycloheximide exhibited inhibition of $\left[{ }^{3} \mathrm{H}\right.$ ]valine incorporation $>80 \%$. WASHED: Slices were incubated $30 \mathrm{~min}$ and then washed for $1 \mathrm{hr}$ before $\left[{ }^{3} \mathrm{H}\right]$ valine was added. Emetine's inhibition was irreversible, whereas cycloheximide's was partially reversible $(* ; t$ test, $p<0.05$ compared to treated slices). B, TREATED: Slices bathed for 30 min in emetine or cycloheximide exhibited complete blockade of LTP $\left(* ; \chi^{2}, p<0.05\right)$. WASHED: These same slices were washed for 2 hr and repetitively stimulated $(20 \mathrm{~Hz} / 10 \mathrm{sec})$ a second time. As in the case of $\left[{ }^{3} \mathrm{H}\right]$ valine incorporation, emetine's blockade of LTP was irreversible, whereas cycloheximide's was reversible.

Whereas evidence has accumulated linking LTP with increased protein synthesis (Browning et al., 1979; Duffy et al., 1981 , it was not previously known whether synthesis of proteins is necessary for LTP. The data presented here suggest that functioning protein synthesis is required for LTP. However, we cannot say whether that role is in the activity-related synthesis of a set of proteins not previously expressed, an increase in the rate of synthesis of a set of proteins already 


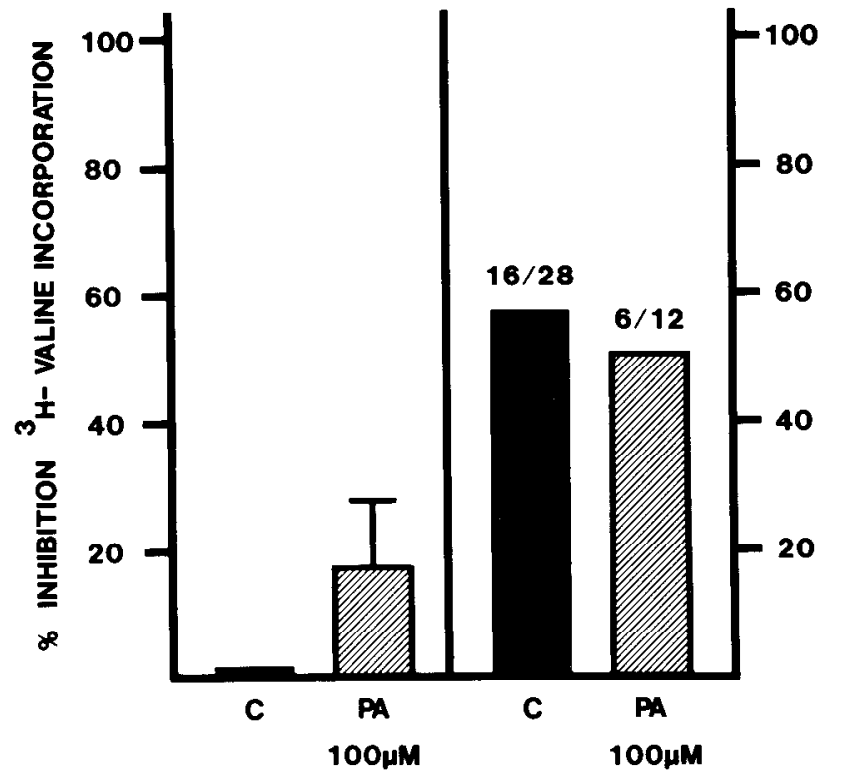

Figure 5. Comparison of the percentage inhibition of $\left[{ }^{3} \mathrm{H}\right]$ valine incorporation by PA with its ability to block LTP in slices. The left axis and hatched bar show the inability of $100 \mu \mathrm{M}$ PA to inhibit $\left[{ }^{3} \mathrm{H}\right]$ valine incorporation as measured by the same paradigm employed for the other inhibitors. The right axis and hatched bar show that $100 \mu \mathrm{M}$ PA was also unable to block LTP in CA1 when tested with the same paradigm as employed for the other inhibitors. 'The solid bars show the control $(C)$ values.

TABLE I

Emetine has no nonspecific effects on intracellular membrane properties

Intracellular recordings were taken from $\mathrm{CA} 1$ pyramidal neurons to measure directly the effect of emetine $(15 \mu \mathrm{M})$ on membrane parameters $(N=5)$. After impalement and stabilization for $30 \mathrm{~min}, 15 \mu \mathrm{M}$ emetine (the highest concentration used to block LTP) was added to the bath for $30 \mathrm{~min}$. No change in any intracellular membrane properties was seen. All slices were then repetitively stimulated via the Schaffer collaterals $(20 \mathrm{~Hz} / 10 \mathrm{sec})$, and no LTP was seen in any slice.

\begin{tabular}{lcc}
\hline \multicolumn{1}{c}{ Parameter $^{a}$} & Pre-Emetine & 30 Min Post-Emetine \\
& \multicolumn{2}{c}{ mean } \\
& \multicolumn{2}{c}{ SEM } \\
RMP (mV) & $-58.2 \pm 1.38$ & $-59.4 \pm 1.0$ \\
$R_{\text {input }}($ megohms) & $16.56 \pm 1.03$ & $16.02 \pm 1.76$ \\
AP amplitude $(\mathrm{mV})$ & $79.14 \pm 1.9$ & $77.44 \pm 1.36$ \\
AP duration $(\mathrm{HAD} ; \mathrm{msec})$ & $0.782 \pm 0.02$ & $0.814 \pm 0.024$ \\
EPSP amplitude $(\mathrm{mV})$ & $10.96 \pm 1.21$ & $10.68 \pm 1.31$ \\
IPSP amplitude $(\mathrm{mV})$ & $6.015 \pm 0.72$ & $6.0 \pm 0.82$ \\
Threshold $(\mathrm{mA})^{c}$ & $0.111 \pm 0.017$ & $0.134 \pm 0.023$ \\
AHP amplitude $(\mathrm{mV})^{d}$ & $4.96 \pm 1.17$ & $5.77 \pm 1.33$ \\
\hline
\end{tabular}

${ }^{a} \mathrm{RMP}$, resting membrane potential; $R_{\text {input, }}$ input resistance; AP, orthodromic action potential; HAD, half-amplitude duration.

${ }^{b}$ None of these values were statistically significantly different from pre-emetine values even at the $p<0.20$ level (paired $t$ test).

c Threshold stimulus strength for orthodromic action potential.

${ }^{d} \mathrm{AHP}$, afterhyperpolarization following a 1-nA, 100-msec depolarizing current step (see Fig. 6).

being synthesized, a requirement for a set of rapidly turned over proteins, or some combination of all three.

Although there is some variability, the dose-response relations for blockade of LTP and inhibition of incorporation of $\left[{ }^{3} \mathrm{H}\right]$ valine into proteins are correlated. Furthermore, there appears to be a requirement for very substantial inhibition of protein synthesis before production of LTP is blocked. This is interesting, considering that there is a similar requirement for

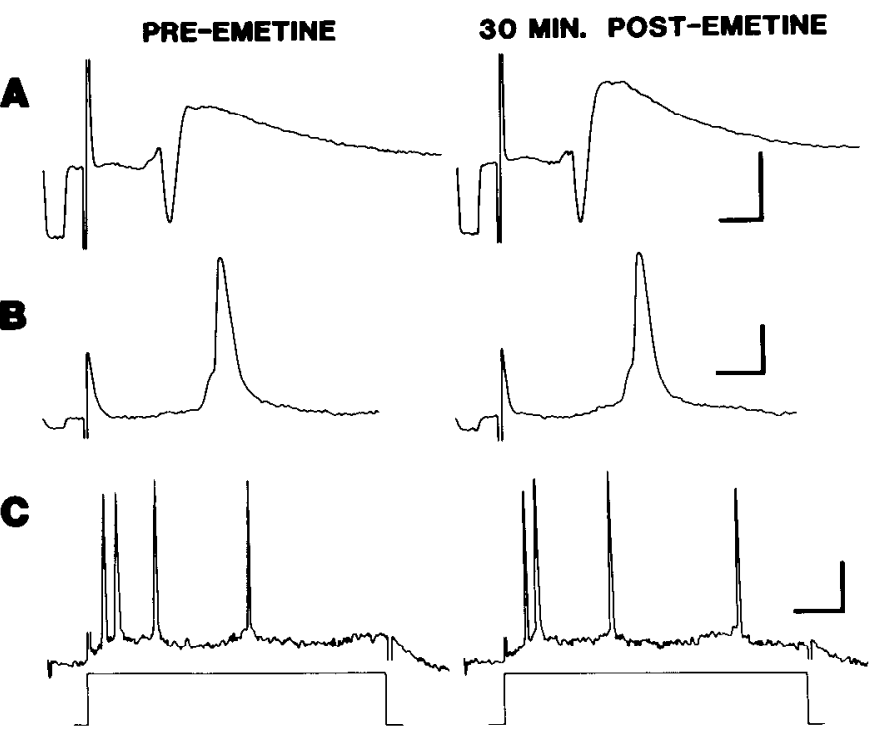

Figure 6. Emetine $(15 \mu \mathrm{M})$ has no nonspecific effects on CA1 pyramidal neurons. $A$, Extracellular population spike in CA1 before ( $P R E$ EMETINE) and $30 \mathrm{~min}$ after (30 MIN. POST-EMETINE) addition of emetine to the bath. The population spike waveform and amplitude were not affected by emetine. Calibration: $5 \mathrm{mV}, 2 \mathrm{msec}$. $B$, Intracellular orthodromic action potential from a $\mathrm{CA} 1$ pyramidal neuron, recorded at threshold stimulus strength, in the same experiment before and 30 min after addition of emetine. The action potential and its threshold were also unchanged. Resting membrane potential, $-60 \mathrm{mV}$; calibration: $20 \mathrm{mV}, 2 \mathrm{msec}$. $C$, Response (upper trace) to a depolarizing current stcp $(1 \mathrm{n} \Lambda, 100 \mathrm{msec}$; lower trace $)$ in the same cell as in $b$, before and $30 \mathrm{~min}$ after addition of emetine. The number of action potentials (four) evoked by the current step as well as the subsequent afterhyperpolarization (not shown) were unchanged. Calibration: $20 \mathrm{mV}, 20 \mathrm{msec}$.

the amnestic effects of these inhibitors (Barondes and Cohen, 1967; Barondes, 1970).

Furthermore, the requirement of a preincubation period for blockade of LTP by emetine suggests that inhibition of protein synthesis needs to be effective at or fairly soon after the repetitive stimulation. Further experiments to determine the precise time course of the blockade of LTP will be important in identifying the kinds of proteins, what post-translational processing may be possible, and their sites of synthesis and action in supporting LTP.

Although the primary effect of these compounds is inhibition of protein synthesis, neuronal side effects have been reported for some of these inhibitors. Cycloheximide and puromycin have been shown to have a direct local anesthetic effect, but at concentrations significantly higher than those used in our studies (Paggi and Toschi, 1971). In our slice preparation, the low and intermediate concentrations of cycloheximide had no effect on population spike amplitude or waveform when present up to $2 \mathrm{hr}$. However, the highest dose of cycloheximide exhibited an ability to transiently increase and then depress population spike amplitude. Puromycin injected intracerebrally in mice produces striking epileptiform abnormalities in hippocampal theta rhythm, but these effects occur $5 \mathrm{hr}$ after injection (Cohen et al., 1966). In our slice preparation, there is no effect of puromycin on population spike amplitude or waveform for up to $3 \mathrm{hr}$. However, in some slices followed for longer time periods, multiple evoked population spikes are sometimes observed. Given the delayed onset of these effects, we believe that they are not important in LTP blockade.

One of the side effects exhibited by some of these protein synthesis inhibitors which has been proposed as a possible explanation for their neuronal effects on behavior is inhibition of catecholamine synthesis (Flexner and Goodman, 1975). 
However, preincubation with the irreversible tyrosine hydroxylase inhibitor AMPT indicated that inhibition of catecholamine synthesis will not block LTP in CA1.

The general consensus has been that anisomycin and emetine are relatively specific protein synthesis inhibitors lacking many of the side effects attributed to other inhibitors (Barondes, 1970; Flood et al., 1973; Dunn, 1976). In fact, extracellular population spike amplitudes and waveforms show no significant changes with bath application of either emetine or anisomycin, at any of the concentrations tested, for several hours. Furthermore, CA1 pyramidal neurons appear to be completely unaffected by the highest concentration of emetine in a wide range of intracellularly recorded membrane parameters.

The specificity of the blockade of LTP was demonstrated in two ways. First, even the highest concentration of emetine employed to block LTP does not alter the waveform of the extracellular field potential or any of the pre- and postsynaptic membrane properties we measured by intracellular recording. Second, the short-term example of activity-related plasticity we call STP cannot be blocked by inhibition of protein synthesis. Previous studies have shown that STP is not a necessary condition for production of LTP (Misgeld et al., 1979). It has also recently been shown that specific blockade of postsynaptic population spike firing with tetrodotoxin, $\gamma$-aminobutyric acid, or pentobarbital blocks production of LTP, without affecting the production of STP (Scharfman and Sarvey, 1983). Our results further support a sharp differentiation between STP and LTP.

The ability of three protein synthesis inhibitors with differing mechanisms of action to block LTP, the close parallel in doseresponse relations for blockade and inhibition of $\left[{ }^{3} \mathrm{H}\right]$ valine incorporation, and the close parallels in time course and reversibility all support the conclusion that these inhibitors block LTP by inhibiting protein synthesis. However, these results conflict with the inability of anisomycin to prevent LTP, although our studies indicate that anisomycin may be able to reduce the amplitude of LTP when it does occur. Although we have ruled out a longer time lag in the drug's effectiveness, inactivation of the drug over time, or inhibition of valine uptake as possible explanations for this difference, other possible explanations remain to be tested. It is important to remember that our use of $\left[{ }^{3} \mathrm{H}\right]$ valine incorporation to measure inhibition of protein synthesis is an overall measure of such synthetic rates and may not reflect a relative resistance of a subclass of protein synthesis to anisomycin. Indeed, Steward and Levy (1982) have visualized a subclass of ribosomes localized to the dendritic spines of hippocampal neurons. Studies of the pharmacology of these uniquely placed ribosomes may prove very fruitful, and anisomycin may prove to be a useful tool in determining what components of protein synthesis are important in the production of LTP.

A large amount of data has accumulated correlating the appearance of newly synthesized proteins in the hippocampus with acquisition of a learned behavior (Hydén and Lange, 1970, 1983). Also, it has been shown that the production of LTP in the hippocampus is associated with a preferential increase in the synthesis of proteins destined for secretion into the extracellular space (Duffy et al., 1981). However, our present results supply the first evidence suggesting a necessity for protein synthesis in the production of LTP, since the inhibition of protein synthesis is correlated with inhibition of LTP. Future lines of investigation should include production of antibodies to some of the specific protein fractions affected by repetitive stimulation or training, and examination of their ability to modify the production of LTP in the hippocampus. Such data might serve both to identify the specific proteins necessary for the production of LTP and also to strengthen the linkage between proteins important to LTP and those important in mechanisms of behavioral plasticity.

\section{References}

Agranoff, B. W., R. E. Davis, and J. J. Brink (1966) Chemical studies on memory fixation in goldfish. Brain Res. 1: 303-309.

Alger, B. E., and T. J. Teyler (1976) Long-term and short-term plasticity in the CA1, CA3, and dentate regions of the hippocampal slice. Brain Res. 110: 463-480.

Andersen, P., 'T. V. P. Bliss, and K. K. Skrede (1971) Unit analysis of hippocampal population spikes. Exp. Brain Res. 13: 222-238.

Andersen, P., S. H. Sundberg, O. Sveen, and H. Wigström (1977) Specific long-lasting potentiation of synaptic transmission in hippocampal slices. Nature, 266: 736-737.

Bär, P. R., A. M. Tielen, F. H. Lopes Da Silva, H. Zweirs, and W. H. Gispen (1982) Membrane phosphoproteins of rat hippocampus: Sensitivity to tetanic stimulation and enkephalin. Brain Res. 245: 6979 .

Barondes, S. H. (1970) Cerebral protein synthesis inhibitors block long-term memory. Int. Rev. Neurobiol. 12: 177-205.

Barondes, S. H., and H. D. Cohen (1967) Delayed and sustained effect of acetocycloheximide on memory in mice. Proc. Natl. Acad. Sci. U. S. A. 58: 157-164.

Bliss, T. V. P., and A. R. Gardner-Medwin (1973) Long-lasting potentiation of synaptic transmission in the dentate area of the unanaesthetized rabbit following stimulation of the perforant path. J. Physiol. (Lond.) 232: 357-374.

Bliss, T. V. P., and T. Lømo (1973) Long-lasting potentiation of synaptic transmission in the dentate area of the anaesthetized rabbit following stimulation of the perforant path. J. Physiol. (Lond.) 232: $331-356$.

Browning, M., T. Dunwiddie, W. Bennett, W. Gispen, and G. Lynch (1979) Synaptic phosphoproteins: Specific changes after repetitive stimulation of the hippocampal slice. Science 203: 60-62.

Cohen, H. D., F. Ervin, and S. H. Barondes (1966) Puromycin and cycloheximide: different effects on hippocampal electrical activity. Science 154: 1557-1558.

Douglas, R. M., and G. V. Goddard (1975) Long-term potentiation of the perforant path-granule cell synapse in the rat hippocampus. Brain Res. 86: 205-215.

Dutfy, C., 'I'. J. 'Teyler, and V. E. Shashoua (1981) Long-term potentiation in the hippocampal slice: Evidence for stimulated secretion of newly synthesized proteins. Science 212: 1148-1151.

Dunn, A. J. (1976) The chemistry of learning and the formation of memory. In Molecular and Functional Neurobiology, W. H. Gispen, ed., pp. 347-387, Elsevier-North Holland Biomedical Press, New York.

Flexner, L. B., and R. H. Goodman (1975) Studies on memory: Inhibitors of protein synthesis also inhibit catecholamine synthesis. Proc. Natl. Acad. Sci. U. S. A. 72; 4660-4663.

Flood, J. F., E. L. Bennett, M. R. Rosenzweig, and A. E. Orme (1973) The influence of duration of protein synthesis inhibition on memory. Physiol. Behav. 10: 555-562.

Goldstein, A. (1964) Biostatistics: An Introductory Text, pp. 129-146, MacMillan Co., New York.

Grollman, A. P. (1968) Inhibitors of protein synthesis. J. Biol. Chem. 243: 4089-4094.

Hydén, H., and P. W. Lange (1970) S-100 protein: Correlations with behavior. Proc. Natl. Acad. Sci. U. S. A. 67: 1959-1966.

Hydén, H., and P. W. Lange (1983) Modification of membrane bound proteins of the hippocampus and entorhinal cortex by change in behavior in rats. J. Neurosci. Res. 9: 37-46.

Lipton, P., and C. J. Heimbach (1977) The effect of extracellular potassium concentration on protein synthesis in guinea pig hippocampal slices. J. Neurochem. 28: 1347-1354.

Lowry, O. H., N. J. Rosebrough, A. L. Farr, and R. J. Randall (1951) Protein measurement with the Folin phenol reagent. J. Biol. Chem. 193: 265-275.

Milner, B. (1972) Disorders of learning and memory after temporal lobe lesions in man. Clin. Neurosurg. 19; 421-446.

Misgeld, U., J. M. Sarvey, and M. R. Klee (1979) Heterosynaptic postactivation potentiation in hippocampal CA 3 neurons: Longterm changes of the postsynaptic potentials. Exp. Brain Res. 37 $217-229$.

Paggi, P., and G. Toschi (1971) Inhibitors of protein synthesis involved in memory disruption: A study of their effect on sympathetic ganglion isolated in vitro. J. Neurobiol. 2: 119-128.

Scharfman, H. E., and J. M. Sarvey (1983) Inhibition of post-synaptic firing in the hippocampus during repetitive stimulation blocks longterm potentiation. Soc. Neurosci. Abstr. 9: 677 .

Schwartzkroin, P. A., and K. Wester (1975) Long-lasting facilitation of a synaptic potential following tetanization in the in vitro hippocampal slice. Brain Res. 89: 107-119. 
Squire, L. R., R. Kuczenski, and S. H. Barondes (1974) Tyrosine hydroxylase inhibition by cycloheximide and anisomycin is not responsible for their amnesic effect. Brain Res. 82: 241-248.

Stanton, P. K., and J. M. Sarvey (1983) Blockade of long-term potentiation in rat hippocampal CA1 region by the protein synthesis inhibitors emetine and cycloheximide. Soc. Neurosci. Abstr. 9: 678.
Steward, O., and W. B. Levy (1982) Preferential localization of polyribosomes under the base of dendritic spines in granule cells of the dentate gyrus. J. Neurosci. 2: 284-291.

Swanson, L. W., T. J. Teyler, and R. F. Thompson (1982) Hippocampal long-term potentiation: Mechanisms and implications for memory. Neurosci. Res. Program Bull. 20: 612-769. 